\title{
On the robustness to corrosion in the life-cycle assessment of an existing reinforced concrete bridge
}

\author{
Eduardo S. Cavaco ${ }^{\mathrm{a}, \mathrm{b}}$, Luis A. C. Neves ${ }^{\mathrm{a}, \mathrm{c}}$, Joan R. Casas ${ }^{\mathrm{d}, *}$ \\ ${ }^{a}$ Civil Engineering Department, Universidade NOVA de Lisboa, Quinta da Torre, \\ 2829-516, Monte da Caparica, Portugal \\ ${ }^{b}$ CEris - Civil Engineering Research and Innovation for Sustainability Av. Rovisco Pais \\ 1, 1049-001 Lisboa, Portugal \\ ${ }^{c}$ Nottingham Transportation Engineering Centre (NTEC), Dept. of Civil Engineering, \\ University of Nottingham, NG7 2RD Nottingham, United Kingdom \\ ${ }^{d}$ Civil Engineering Department, Technical University of Catalunya, Modulo C1, \\ Barcelona, Spain
}

\begin{abstract}
Management of existing structures has traditionally been based on condition assessment, based on visual inspections, disregarding the susceptibility of different structural types to aging and deterioration. Robustness, as a measure of the effects of unpredictable damage to structural safety can be a complementary information to the results of inspection. Although robustness has mostly been used to evaluate the consequences of extreme events, a similar framework can be used to investigate the result of aging, allowing a better understanding of the potential effects of deterioration and allowing a better allocation of available maintenance funding. In this work, a probabilistic structural robustness indicator is used to quantify the susceptibility of structures to corrosion. The methodology is exemplified through a case-study comprising an existing reinforced concrete bridge deck, heav-
\end{abstract}

\footnotetext{
${ }^{*}$ Corresponding author

Email address: joan.ramon.casas@upc.edu (Joan R. Casas)
} 
ily damaged due to reinforcement corrosion, and finally demolished due to safety concerns. Robustness measures the bridge deck safety tolerance to reinforcement corrosion. The principal effects of corrosion, including loss of area and bond between concrete and steel are modelled using a non-linear finite element model, coupled with a Response Surface Method to compute the bridge reliability as a function of the corrosion level, and finally used to assess robustness. Results show that the redundancy of the bridge allow significant redistribution of loads between elements with different corrosion levels. As a result, the bridge presents significant robustness and tolerance to reinforcement corrosion.

Keywords: Robustness, Corrosion; Reinforced Concrete; Reliability; Bridge; Tolerance.

\section{Introduction}

Most developed countries have built, over the last decades, a fairly complete network of highways and railways to fit their needs, which are now showing signs of advanced deterioration and aging, and therefore requiring very large investments in maintenance and repair (ASCE, 2013). Since available funding is much lower than the effective needs, management of existing aged and deteriorated civil infrastructures is one of the most challenging is-

sues for civil engineers in developed countries. Due to the importance of bridges in the connectivity of highway and railway networks, maintenance of these structures is crucial, to keep them safe and serviceable. Reinforced concrete has been extensively used worldwide for bridge construction. Reinforcement corrosion is among the most damaging phenomena leading to 
service and safety levels degradation.

The current practice in bridge management is based on reactive maintenance applied when the condition of the bridge, quantified by a visual inspection, is found unacceptable. This strategy disregards the impact of geometry, structural type and materials used on the tolerance of the bridge to damage and deterioration, resulting in sub-optimal decisions. In fact, some structural types, particularly when low redundancy exists or brittle failure is likely, present much higher reduction in safety due to deterioration than redundant and ductile structure with significant strength reserves in alternate load paths.

Tolerance to damage has been mainly linked to robustness, a concept that has received increased interest in the last forty years due to the occurrence of extreme events on structures with resulting devastating consequences. Although research on robustness has mainly focused on damage resulting from an extreme event (Cavaco et al., 2013b), it can also be of extreme utility for aging and deteriorating scenarios where damage develops gradually in time but, as extreme events, is extremely difficult to predict.

This paper presents a framework to assess robustness of deteriorated structures for integration in structural management systems. Although time dependent reliability analysis of structures provides the best estimate of the impact of deterioration on future safety, it is significantly hindered by the difficulties in accurately predicting the deterioration rate of structures. As a result, a deterioration rate independent measure of ability to sustain damage is proposed here and compared with a more traditional time-dependent approach. Damage is considered unknown, and robustness is used to measure 
the loss of safety associated with the entire damage range. A reinforced concrete bridge under advanced deterioration due to reinforcement corrosion will be used as example, as corrosion is the most damaging phenomenon leading to progressive damage. In a previous paper (Cavaco et al., 2016), the authors have shown the application of the present concept to a isostatic structure. In the present paper a highly redundant bridge is investigated

\section{Structural Robustness and Deterioration}

Robustness first received attention due to devastating consequences resulting from extreme events on structures (Frangopol and Curley, 1987; Lind, 1995; Ghosn and Moses, 1998; Baker et al., 2008). Robustness was related to the ability of the structure to sustain damage with limited consequences. Several measures to quantify robustness have been proposed in the literature, mostly focusing on extreme scenarios cases, were progressive collapse is likely to occur (Starossek and Haberland, 2011). Robustness is qualitatively defined in several codes, including the Eurocodes. However, no code presents methodologies to quantify the robustness of a particular structure, and significant discussion exists on the advantages and disadvantages of different methodologies proposed in the literature (Cavaco et al., 2013a).

The first use of an indicator of the influence of damage on safety considering redundancy was introduced by Frangopol and Curley (1987) as:

$$
\beta_{R}=\frac{\beta_{\text {Intact }}}{\beta_{\text {Intact }}-\beta_{\text {damaged }}}
$$

where $\beta_{\text {Intact }}$ is the reliability index of the intact system and $\beta_{\text {damaged }}$ is the reliability index of the damaged system. This concept was extended by Biondini and Restelli (2008) considering that deterioration was unpredictable. 
These authors consider that the variation of structural performance has to be compared with the corresponding amount of damage to provide meaningful information for robustness evaluations. They propose a measure of robustness of reinforced concrete structures under corrosion, including the time factor. To this end, a time-variant measure was proposed in Biondini (2009) and Biondini and Frangopol (2014) to quantify structural robustness. They developed a measure of robustness to deterioration that is time-variant and nonlinear. Cavaco et al. (2013b) developed an indicator of robustness to deterioration in terms of the ability of the structure to keep performing according to the design objectives when damage occurs. Several performance indicators can be used to measure the structure robustness and different damaging scenarios can be considered. Robustness can be measured by a single indicator as:

$$
R=\int_{d=0}^{d=1} f(x) d x
$$

where $f$ is the normalized performance index, given by the ratio between the structural performance on the intact and damage states, and $d$ is the normalized damage, given by the ratio between actual and maximum possible damage. As both performance and damage are normalized, robustness results range from 0 , for a non robust structure where minimal damage level produces total performance loss, to 1 , for a full robust structure where performance is damage independent and equal to the intact structure performance. In this way, the robustness of the structure is defined independently of the initial safety, and is a time-invariant value, but focus on the relative loss of safety due to deterioration. Thus a structure can be defined as robust and unsafe, if the safety level of the intact structure is inadequate but is not affected by 
damage.

A point-in-time measure of robustness as the one defined by Biondini and Frangopol (2014) is adequate to capture those critical scenarios where a small increase of damage due to deterioration may lead to sudden and disproportionate performance deterioration. A maintenance policy seeking to intervene when such scenarios may appear requires this type of robustness definition. However, to define the time/s where these scenarios will occur is really difficult due to the high uncertainties involved in the prediction of the deterioration processes to whom structures are exposed (for instance, corrosion). Accurate deterioration profiles are still by now highly unpredictable and, therefore, exact times where the important loss of damage will occur, are difficult to predict. To this end, also the index proposed in Equation (2) is not of any help as does not take into account these point-in-time aspects. However, it is a helpful tool when deciding where the interventions within a maintenance strategy are more necessary from a life-time and not a pointin-time perspective. This may help operators to decide in which structures allocate more resources as they present less ability to sustain future feasible damage scenarios. Structures with a higher value of $\mathrm{R}$ show higher levels of performance along the whole service life for any feasible damage scenario than others with lower values. In this sense, time-variant and global measures of robustness to deterioration may be complementary depending on the main objectives pursued by the operators/owners in the management of the existing stock.

The approach presented in Cavaco et al. (2013b) defines the structural performance in terms of the load carrying capacity of the structure. How- 
ever, this is not a accurate measure of the structural safety. Moreover, two different structures can have similar robustness indices even if one presents a smooth reduction of performance with deterioration and the other shows a sudden loss of performance at a certain damage level. To overcome this limitation, and to take into account the uncertainties involved, the robustness measure proposed by Cavaco et al. (2013b) is improved by quantifying the performance, $f$ in Equation (2), through the reliability index, $\beta$ (Cavaco et al., 2016). Damage, $d$, produced by corrosion, will be measured in terms of reinforcement bars weight loss percentage, $X_{P}$. In this manner, robustness is defined as an intrinsic structural property for a defined loading scenario and performance indicator, both independent of time and environmental conditions. Robustness results in this manner in a macro-value which translates the damaged structure mean performance considering all possible damage levels as unpredictable. For structures with similar condition, the robustness indicator will define for which structure deterioration has greater consequences and, consequently which structure should have higher priority in a repair plan.

Finally, quantifying robustness of the several structural types within a structural management system, shows the vulnerability of infrastructure to aging and deterioration, allowing the identification of more robust structural solutions.

\section{Time-dependent to time-independent safety}

In the last decade, the reliability analysis of deteriorating structures, in particular, reinforced concrete structures, has been an area of very intense 
research. In spite of all the advances achieved in defining both better structural models (Alipour et al., 2013; Biondini and Vergani, 2015; Lim et al., 2016) and the probabilistic models (Akiyama et al., 2010; Papakonstantinou and Shinozuka, 2013), the uncertainty in future corrosion is very high. This is not a matter of lack of knowledge or understanding, but a consequence of the manifold of factors, including environmental, use, quality of construction and workmanship, which influence the progression of corrosion and cannot be predicted beforehand.

The reliability of a corroding existing structure is a time-dependent problem (Stewart and Rosowsky, 1998; Val et al., 1998). At a first sight, improving the robustness index proposed in Cavaco et al. (2013b) by integrating the reliability index may have the inconvenient of turning it also time-dependent. However, decision making based on such a robustness indicator is unpractical as a time-dependent reliability analysis, based on a sophisticated and accurate structural model, is usually extremely time consuming and involved with significant uncertainity as it requires the assessment of the existing corrosion level and deterioration rate. Thus the time-dependent to timeindependent problem conversion suggested in Melchers (1999) is used. The time-dependent problem can be expressed as:

$$
P_{f}(t)=\int_{G[X(t)]} f_{X(t)}[X(t)] d x(t)
$$

where $P_{f}(t)$ is the instantaneous probability of failure at time $t, X(t)$ is the random variables vector, $G[X(t)]$ is the limit state function and $f_{X(t)}$ the joint probability density function of the random variables. The instantaneous probability of failure can be integrated over an interval of time, $[0 ; t]$, resulting in the probability of failure over that time period, $P_{f}(0, t)$. The random 
variables, $X(t)$, are time dependent and, thus, so is $P_{f}(t)$. The time $t$ at which the limit state function, $G[X(t)]$, becomes zero is denoted time-tofailure and Equation (3) correspond to a first-passage-probability, assessed with the out-crossing theory (Melchers, 1999).

Time-integrated approaches for solving Equation (3) are much simpler, as lifetime maximums distributions for loads are used as presented in Equation (4)

$$
P_{f}(0, t)=P\left(R(t) \leq S_{\max }(t)\right)
$$

where $R(t)$ is resistance and $S_{\max }(t)$ is the maximum load effect for the time period $[0 ; t]$. However, as resistance is also time dependent, decreasing with deterioration, it is extremely unlikely that the maximum load effect coincides with the time of minimum resistance. By dividing structure lifetime into $n$ limited time periods, for which resistance can be considered as time invariant, it is possible to approach the first-passage problem by Equation (5):

$$
P_{f}(0, t)=1-P\left(R_{1} \geq S_{\max , 1} \cap R_{2} \geq S_{\max , 2} \cap \ldots \cap R_{n} \geq S_{\max , n}\right)
$$

where $R_{i}$ respect to resistance at time interval $\left[t_{i-1} ; t_{i}\right]$, considered as constant, and $S_{\max , i}$ is the maximum load effects within the same period. Despite the independence of $S_{\max , i}$ between time periods, the subset of events presented in Equation (5) still show some dependency as a result of the correlation between remaining involved variables. The probability of failure can finally by estimated using the narrow reliability bounds proposed by Ditlevsen (1979), as a comparison between Equation (5) and that relative to a serial system can be established. Thus, if relative short time periods are considered, attending to the expectable corrosion rate, the probability of 
failure, given a certain level of corrosion, can be considered approximately as constant. The corresponding reliability index, $\beta$, is therefore used herein as the time-independent performance indicator and Equation (2) results in:

$$
R=\int_{0}^{1} \frac{\beta\left(X_{P}=x\right)}{\beta\left(X_{P}=0\right)} d x
$$

Robustness, defined as Equation (6), provides a relative measure of the structure tolerance to corrosion not dependent of time and corrosion rate and on the existing corrosion level. Moreover, for more robust structures, the time-dependent probability of failure defined by Equation (5), will increase at a reduced rate when compared to that of less robust structures.

\section{Corrosion of reinforced concrete structures}

\subsection{Corrosion deteriorating effects}

Reinforcement bars are made of steel, an iron and carbon alloy, which absorbs energy during the manufacturing process. Steel bars, when exposed to environmental conditions, tend to release part of that energy on an exothermic reaction called corrosion. The sub products of this reaction are iron oxides with very poor mechanical properties and several times (up to seven) bulkier than the original steel material. It is possible to slow down corrosion but is impossible to completely avoid it. Research has also shown that corrosion is a highly complex and sensitive phenomenon depending on a manifold of factors such as atmosphere chemical composition, temperature, humidity, potential, wind, steel stress, among others. Consequently, it is impossible to accurately predict where and when corrosion will occur on structures and at what rate. 
For structural proposes, more relevant than corrosion itself, are the resulting deteriorating effects. The most direct effect is the reinforcement effective area reduction, as mechanical properties of resulting iron oxides are not comparable to those of steel. Due to bulkier nature of these, concrete cracking and spalling, as well as bond degradation between steel bars and surrounding concrete, are also expected deteriorating effects. A ductility reduction of steel bars may also be experienced in cases of non uniform corrosion. Partially due to chemical phenomenon called hydrogen embrittlement, more prone to occur on high strength bars (Schroeder and Müller, 2003; Woodtli and Kieselbach, 2000), but fundamentally due to localized corrosion spots, which tend to result in localized high strains and therefore in decreased steel bars ductility.

In the last decades, several studies have been devoted to study corrosion and its effects on structural concrete. Research has shown (Al-Sulaimani et al., 1990; Almusallam et al., 1996; Mangat and Elgarf, 1999; Azher, 2005; Al-Hammoud et al., 2010; Kivell et al., 2012) bond degradation between steel bars and concrete to be a major cause for impaired load carrying capacity of structural members subjected to bending and uniform corrosion. This is aggravated in the presence of insufficient and/or corroded anchorages and/or lapped joints, as suggested by Murakami et al. (2006). Additionally, corrosion tends to be more pronounced for folded bars and in areas of reinforcement concentration as transition zones and lapped joints. Research has also shown that generalized corrosion usually results in concrete cover cracking and spalling which tend to exacerbate steel bars exposure, corrosion and bond deterioration. Concrete cracking and spalling may also impair 
structural behavior, in particular if occurs in areas subjected to compressive stresses.

When corrosion is not uniform along steel bars length and the corrosion rate is significantly higher in specific spots, localized higer reinforcement area reduction and formation of pits will occur (Stewart, 2004; Stewart and AlHarthy, 2008). Area reduction in certain pits can reach up to seven times the average area lost along bar length (Gonzalez et al., 1995; Rodriguez et al., 1996; Pina, 2009). Therefore, when localized corrosion takes place, reinforcement area reduction including bar decreased ductility, due pits strain localization, are the fundamental factors causing impaired structural behavior.

\subsection{Corrosion Modelling}

On the following paragraphs, a strategy for modelling corrosion deteriorating effects, simple to implement on a general finite element package, will be described. The strategy presents herein is based on a modification of the steel constitutive behavior and on the slipping-fiber model proposed by Oliver et al. (2008). This model condenses in an single constitutive relation both reinforcement and bond to concrete constitutive laws. The sipping-fiber model consist on two springs linked in series, one modelling the steel bar and the second the interface between steel and concrete. The slipping-fiber strain, $\epsilon^{f}$, is composed of two parts:

$$
\epsilon^{f}=\epsilon^{d}+\epsilon^{i}
$$

where $\epsilon^{d}$ is the rebar mechanical strain while $\epsilon^{i}$ accounts for the relative slip at the interface. As the two springs are coupled in a serial system the corresponding slipping-fiber stress $\sigma^{f}$ is identical to the stress in rebar $\left(\sigma^{d}\right)$ and 
interface $\left(\sigma^{i}\right)$. For both components, a one-dimensional bi-linear constitutive model is considered, as shown in Figure 1. Thus, the constitutive behavior of the slipping-fiber is also bi-linear, conditioned by the weakest spring, and characterized by the following parameters:

$$
\begin{gathered}
\sigma_{y}^{f}=\min \left(\sigma_{y}^{d}, \sigma_{y}^{i}\right) \\
E^{f}=\frac{1}{\frac{1}{E^{d}}+\frac{1}{E^{i}}} \\
H^{f}=\left\{\begin{array}{l}
H^{d}, \text { if } \sigma_{y}^{d}<\sigma_{y}^{i} \\
H^{i}, \text { if otherwise }
\end{array}\right.
\end{gathered}
$$

where $E$ and $H$ are the Young's modulus and softening parameter, respectively, upper indexes $d, i$ and $f$ refer to steel, interface and resulting slippingfiber, respectively, and bottom index $y$ represent the yielding stress.

[Figure 1 about here.]

Steel fiber parameters may be obtained from tensile tests while those respecting to the interface may be derived from pull-out tests and the resulting tensile force-displacement curve.

In order to account for corrosion deteriorating effects, it is necessary to consider the area loss of rebars and to update the interface constitutive model parameters $\left(\sigma_{y}^{i}, E^{i}\right.$ and $\left.H^{i}\right)$ to account for bond deterioration. If steel ductility reduction is considered, steel model parameter $\left(\sigma_{y}^{d}, E^{d}\right.$ and $\left.H^{d}\right)$ must also be updated.

\section{Case study}

\subsection{Description of the bridge}

Tercenas bridge was built in 1968 in the Leiria distric, in the Center of Portugal. The bridge had been regularly inspected since 2004 and signs of 
progressing advanced deterioration had been detected year after year, specially in the bridge deck. The bridge was finally closed in October 2011 and demolished in November 2012.

The reinforced concrete deck was divided in three continuous spans of $18.60 \mathrm{~m}, 22.80 \mathrm{~m}$ and $18.60 \mathrm{~m}$. The $8.90 \mathrm{~m}$ wide deck was composed by four $\mathrm{RC}$ girders connected at the top by a concrete slab providing the traffic lanes and the sidewalks for the pedestrians (see Figures 3 and 4). The girders had $1.25 \mathrm{~m}$ height and variable width between $1.10 \mathrm{~m}$ at the supports and $0.50 \mathrm{~m}$ at the mid-span. The girders width transition was linear on the first $1 / 3$ of the span and, at each $1 / 3$ of the span, a crossbeam with $1.25 \mathrm{~m}$ height and $0.30 \mathrm{~m}$ wide connects all the girders providing transverse stiffness to the bridge deck (see Figure 2). The three spans were supported by abutments in the river margins and piers in the riverbed. Due to poor soil mechanical properties, all the vertical supports were founded on piles.

[Figure 2 about here.]

On the girders top, a single layer of $16 \phi 25$ provided reinforcement to resist bending effects over the supports. On the lateral spans, bottom reinforcement consisted on a three layers of $5 \phi 25$ rebars. On the central span, two bottom rebar layers existed, one external layer with $6 \phi 25$, followed by a second inner layer of $5 \phi 25$.

[Figure 3 about here.]

\subsection{Bridge Condition}

Tercenas bridge had been regularly inspected by the Portuguese National Laboratory of Civil Engineering since 2004 which conclude the bridge condition was aggravating, increasing the concerns about the short term bridge 
safety. In March 2011, Jacinto (2011) carried out a detailed visual inspection of Tercenas bridge, having found the most concerning pathology to be the generalized corrosion of the bottom reinforcement of deck girders. Although no chemical tests were performed, probably corrosion was due to chloride contamination due to the bridge proximity to the coast. Figure 4 shows a photo taken from the west-side of the bridge. It is possible to observe generalized corrosion in all girders, and concrete cover cracking and spalling, in some cases. Figure 4 and Figure 5 also show corrosion on girder 1 to be more advanced than that observed in the remaining girders.

[Figure 4 about here.]

During the inspection carried out in March 2011 (Jacinto, 2011), an attempt was made to assess the corrosion degree by measuring the effective reinforcement area after cleaning the rebars from steel oxides. Reinforcement area lost was found to be approximately uniform and equal to $50 \%$ over the girder span. Clearly a rough estimation of the real corrosion level, since no specimens were taken from the girder and carefully inspected. Corrosion was also preferably measured in girder 1 , that most corroded. Remaining girders were significantly less corroded, however it was not possible to estimate the respective reinforcement area loss. It was also not possible to assess corrosion level on the most inner reinforcement layers.

The evaluation of present corrosion depth in reinforced concrete structures is complex, in particular for inner reinforcement layers. Moreover, predicting future deterioration at any stage of the bridge life (i.e., design, new bridge or deteriorated bridge) is associated with very large uncertainty and relies 
strongly on experts' opinion. By considering corrosion as an unpredictable event, and using tools and methods based on robustness concepts, an alternative indicator of resistance to deterioration can be proposed, which is much less influenced by experts' opinion and on an extremely difficult to predict deterioration rate.

Corrosion of the transverse reinforcement was found to be almost negligible. Considering also that the bridge deck girders were designed with an over-width close to the supports, a shear failure was considered unlikely to occur.

[Figure 5 about here.]

\subsection{Bridge Numerical Model}

The structural system used in Tercenas bridge, consisting on main longitudinal girders topped by a concrete slab, has been widely modeled using finite elements and grid frame models (Ghosn and Moses, 1998). This type of numerical model is much lighter than modeling reinforced concrete using plane stress finite elements which is a great advantage having in consideration that it was to be used for a reliability analysis.

A tridimensional finite element model of the Tercenas bridge deck was built using the OpenSees software (Mazzoni et al., 2005) (see Figure 6). For the deck girders nonlinear force-based finite elements were used. For the cross sections, multi fiber models with distributed plasticity were adopted. In order to account for transversal load redistribution, provided by the top slab and the crossbeams at $1 / 3$ of the span, two additional frame models were defined. In both cases, non-linear force based finite elements with distributed plasticity were used. 
[Figure 6 about here.]

A zero tensile strength with compression softening constitutive relation ("Concrete01" in OpenSees, adapted from (Yassin, 1994)) was defined for Tercenas bridge concrete. For steel fibers, the slipping-fiber model described in the previous section was used.

The effect of concrete cracking and spalling in the tension zones was indirectly considered by assuming a zero tensile strength material. In the compression zones the effect was not addressed as here concrete was found to be in good conditions. In the length of positive bending moments concrete under compression was intact due to pavement protection, and in the length of negative bending moments, near the supports, concrete was found to be not cracked and the cross sections exhibited over width, as shown in Figure 5.

Reinforcement area reduction due to corrosion was considered by reducing, in the numerical model, steel fibers area. Ductility reduction was neglected since corrosion, according to the inspection carried out by Jacinto (2011), was found to be uniform along bars length, without significant pits. Therefore negligible strain localization was expected. Bond characterization based on pull-out tests was not possible since no specimens could be extracted from the bridge deck. However, corrosion influence on bond degradation has been the aim of a manifold of experimental studies (Al-Sulaimani et al., 1990; Cabrera, 1996; Rodriguez et al., 1994; Almusallam et al., 1996; Amleh and Mirza, 1999; Auyeung et al., 2000; Lee et al., 2002; Fang et al., 2004). Although significant research efforts have been devoted to the topic, an unequivocal relation between bond degradation and the observed corrosion 
level on reinforcement is still hard to establish due to scattered data found in the referred studies. As a result, Bhargava et al. (2007) have proposed the $M$-pull model, a regression model based on the available experimental data on pull-out test of corroded specimens. The $M$-pull model provides a mean value of the residual normalized bond strength as a function of the corrosion level, $X_{P}$, on the reinforcement, measured in terms of weight loss percentage. This model is summarized on (11) and it was used to characterise the slipping-fiber model, in particular the interface spring.

$$
\frac{\sigma_{y}^{i}\left(X_{P}\right)}{\sigma_{y}^{i}\left(X_{P}=0\right)}=\left\{\begin{array}{cc}
1.0 & \text { if } X_{P} \leq 1.5 \% \\
1.192 \cdot e^{-0.117 X_{P}} & \text { if } \quad X_{P}>1.5 \%
\end{array}\right.
$$

The interface stiffness was disregarded as well as the softening parameters of both steel-fiber and the interface, due to negligible effect on maximum load carrying capacity of main girders. Remaing properties of the steel fiber were characterized according to steel grade used for building Tercenas bridge.

\section{Reliability Analysis}

\subsection{Probabilistic properties}

Eight random variables were considered in the present study. Describing the resistance model, concrete compressive strength $f_{c}$, steel strength $f_{y}$,

reinforcement rebars area $A_{s}^{\phi 25}$ and the associated model uncertainty $\theta_{R}$, were considered as random variables. For the load model description, four random variables were considered: concrete self-weight $\gamma_{c}$, remaining dead loads $\gamma_{d l}$, live loads related to traffic $\gamma_{t l}$ and load model uncertainty $\theta_{E}$.

For the concrete characterization, nine specimens were extracted from the bridge deck and tested for the compressive strength $f_{c}$ (Jacinto, 2011). A 
lognormal distribution was assumed, following Vrouwenvelder (1997), with a mean of $51.2 \mathrm{MPa}$ and a standard deviation of $13.2 \mathrm{MPa}$. Concrete tension strength, $f_{t}$, was considered negligible.

Although no specimens were extracted from the bridge, the original design drawings define an A40 steel grade. Accordingly to the Probabilistic Model Code (Faber and Vrouwenvelder, 2000), reinforcement strength can be considered normally distributed with mean yielding stress $\mu_{1}$ given by:

$$
\mu_{1}=S_{n o m}+2 \sigma_{1}
$$

where $S_{n o m}$ is the minimum specified yield stress limit, accordingly to the steel grade, and $\sigma_{1}$ is the overall standard deviation that can be taken equal to $30 M P a$. Thus a normal distribution with mean value $460 \mathrm{MPa}$ and standard deviation $30 \mathrm{MPa}$ was adopted. For the $\phi 25$ rebars area, $A_{s}^{\phi 25}$, a normal distribution was adopted, with mean value equal to the nominal area and a 0.02 coefficient of variation, as proposed by Faber and Vrouwenvelder (2000). There is little information regarding the accuracy of resistance models in reliability analysis. Faber and Vrouwenvelder (2000) suggested a lognormal distribution with 1.05 mean value and $10 \%$ covariation for the resistant model, considering an undeteriorated structure and traditional resistance models. In the present case, deteriorated structures are being analysed, which increases the complexity of the mechanical models, and consequently the uncertainty in the models. On the other hand, a more advanced non-linear finite elements model is being used, which reduces uncertainty. Considering the lack of available information on the effect of these two factors on the model uncertainty, it is herein assumed that the proposal of Faber and Vrouwenvelder (2010) is valied. 
Concrete self-weight was considered normally distributed with mean equal to $25 \mathrm{kN} / \mathrm{m}^{3}$ and standard deviation equal to $0.75 \mathrm{kN} / \mathrm{m}^{3}$. For the remaining dead loads, related to side walks, guard rail and asphalt, a normal distribution with $10 \%$ coefficient of variation was adopted as suggested by von Scholten et al. (2004). The mean value was estimated by analysing the original bridge technical drawings.

Since there were no traffic records available for Tercenas bridge, traffic load effects proposed by CEN (2002) were considered. The 7.0m bridge lane was divided into three sublanes, two with $3.0 \mathrm{~m}$ of width and one with $1.0 \mathrm{~m}$. On the first $3.0 \mathrm{~m}$ lane, an uniform nominal load of $9.0 \mathrm{kN} / \mathrm{m}^{2}$ was considered and on the remaining lanes $2.5 \mathrm{kN} / \mathrm{m}^{2}$ were applied. Two axle vehicles with $2.0 \mathrm{~m}$ distance between axles were considered acting simultaneously with the uniform load on the two first lanes. On the first and second lanes $300 \mathrm{kN}$ and $200 \mathrm{kN}$ nominal load/axle vehicles were considered, respectively. The heaviest loaded lane was defined preferentially over girder 1 (the most corroded) and girder 2, to account for the worst case scenario. All traffic loads were modelled as normal distributions, considering the nominal values described above as the 95\% percentile (von Scholten et al., 2004; Cremona et al., 1999). For sake of simplicity, these loads were assumed linearly dependent on a scale factor $\gamma_{t l}$ which $95 \%$ percentile was equal to unity, $\gamma_{t l}^{95 \%}=1$, and considered normally distributed. Maximum loads for a period of $n$ years were assumed to have a Gumbel distribution with parameters $\nu_{n}$ and $\alpha_{n}$, and where the mean value, $\mu$, and standard deviation, $\sigma$, can be obtained by (Tang and 
Ang, 2006):

$$
\begin{gathered}
\mu=\mu_{n}+\frac{\gamma}{\alpha_{n}} \\
\sigma=\frac{\pi}{\sqrt{6} \alpha_{n}}
\end{gathered}
$$

where $\gamma$ is the Euler constant equal to 0.5772157. In this case, the Gumbel distribution is considered to describe the maximum distribution for the traffic loads scale factor, $\gamma_{t l}$. Thus, from the cumulative Gumbel distribution it is possible to obtain the respective mean value:

$$
\mu=\frac{\gamma_{t l}^{95 \%}}{1+1.866 V_{\gamma_{t l}}}
$$

where $V_{\gamma_{t l}}$ is the coefficient of variation for the traffic loads scale factor, $\gamma_{t l}$. A $20 \%$ variation coefficient was adopted for the maximum traffic loads distribution and a 100 years reference period. Equation (15) results in a mean value $\mu=0.728$ and a standard deviation of $\sigma=0.20 \times 0.728=0.146$. Gumbel distribuion parameters result equal to $\nu_{n}=0.663$ and $\alpha_{n}=8.806$ from equations (13) and (14). For shorter reference periods, the Gumbel parameteres $\left(\mu_{1}, \alpha_{1}\right)$ can be computed as:

$$
\begin{gathered}
\mu_{n}=\mu_{1}+\frac{1}{n} \ln (n) \\
\alpha_{n}=\alpha_{1}
\end{gathered}
$$

Finally, to account for the uncertainties associated with the load models, a lognormal random variable, $\theta_{E}$, was considered, following Faber and Vrouwenvelder (2000), with mean value equal to 1.0 and coefficient of variation equal to $10 \%$. 
Table 1 shows the distributions and parameters of the eight random variables considered in this study. The material properties were considered constant over the entire structure.

[Table 1 about here.]

\subsection{Time-independent reliability analysis}

Neglecting the initiation period, mean corrosion rate in terms of reinforcement weight loss for Tercenas bridge was estimated, based on results of inspections, as 1.14\%/year. Thus, short periods of 6 months were considered for the time-integrated approach, and resistance was considered constant within this period. The maximum traffic loads effects were derived from the lifetime maximum distribution and the First Order Reliability Method (FORM) (Haldar and Mahadevan, 2000), was used to compute the probability of failure within this time period, considering increasing corrosion ratios. The limit state function, $G$, was defined as the difference between the resisting and maximum acting traffic loads effects for the period of 6 months:

$$
G=\gamma_{r l}-\gamma_{t l}
$$

where $\gamma_{t l}$ is the scale factor applied to the traffic loads effects and $\gamma_{r l}$ is the maximum traffic load scale factor, the bridge deck supports, when simultaneously subjected to traffic and the remaining dead loads. $\gamma_{r l}$ correspond to the resisting/applied load ratio obtained from a non-linear analysis of the OpenSees bridge model, carried out by imposing and controlling the midspan vertical displacement of the central span up to the structure failure. It is a function of:

$$
\gamma_{r l}=\gamma_{r l}\left(f_{c} ; f_{y} ; A_{s}^{\phi 25} ; \theta_{R} ; \gamma_{c} ; \gamma_{d l} ; \theta_{E}\right)
$$


Since it was not possible to obtain an explicit expression for the limit state function $G$, a response surface approach, in the design point, $d_{p}$, neighborhood was used (Bucher, 2009):

$$
\widetilde{G}=a_{0}+\sum_{i=1}^{N} a_{i} x_{i}+\sum_{i<j}^{N} a_{i j} x_{i} x_{j}+\sum_{i=1}^{N} a_{i j} x_{i}^{2}+\ldots
$$

where $\widetilde{G}$ is the explicit surface approach for $G, N$ is the number of predictable variables $x_{i}$, eight in this case, and $a_{i j}$ are the model coefficients. A quadratic approach was adopted for the limit state function response surface, resulting in 45 model coefficients. Thus 45 different support points in the design point neighborhood, and respective limit state function evaluations were needed. Although, with some minor adjustments, the latin hypercube sampling technique, as proposed by Olsson et al. (2003), was used to obtain an uncorrelated sample of 45 support point near the design point. The main difference from the original LHS method was that instead of using the respective distributions for the random variables, a pseudo-Gaussian distribution with the respective design value as the mean value was used for each variable, resulting in an uncorrelated sample of support points normally distributed over the design point periphery. This was fundamental for the success of the response surface accuracy. For the standard deviation of the pseudoGaussian distribution it was found, by experimentation, that a percentage of $25 \%$ of the real standard deviation lead to faster convergence of the FORM algorithm due to an optimization of the response surface accuracy and domain. Using higher standard deviations lead to a spreader sample of support points around the design point, resulting in a more embrancing, however less accurate, response surface, and vice-versa. 


\section{Results and Discussion}

\subsection{Reliability Analysis}

Figure 7 show the time-independent probability of failure and the reliability index of Tercenas bridge, depending on corrosion level and assuming a deterministic deterioration rate. Corrosion was considered up to 100\%, for the outmost reinforcing steel, although it is believed that in practice this is unrealistic. The goal was to depict the minimum possible safety threshold if any repair works are carried out during the process. Although girder 1 had been detected with severe damage, corrosion, for the remaining girders, was considered, in this stage, the same. Corrosion was considered to affect only the first layer of the bottom reinforcement as the inner layers were expected to keep intact, resulting in a maximum possible lost of $1 / 3$ and $1 / 2$ of the total bottom reinforcement, for the lateral and central bridge spans, respectively. Corrosion on top reinforcement was considered negligible due to bituminous protection and correct waterproofing.

For the uncorroded structure the probability of failure within the period of 6 months resulted in $5 \times 10^{-10}$ which correspond to a reliability index of 6.1. For a period of 1 year the bridge reliability resulted in 6.0 which is above

the Eurocode recommendation (5.2) for structures within the higher class of consequences.

[Figure 7 about here.]

Figure 7 also show the safety levels reduction to be more pronounced for corrosion levels below 40\%. At the time the bridge was demolished, corrosion on girder 1 was estimated to be around $50 \%$ which correspond to a probability 
of failure equal to $4.7 \times 10^{-7}$ and a reliability index of 4.9 , within the period of half a year.

The residual capacity is mostly affected by the reduction in the tension force carried by steel reinforcement. If corrosion is very localized and, consequently, the loss in bond between concrete and steel is not relevant, the reduction in tension force is proportional to the loss of reinforcement crosssection area. In this case, the minimum residual capacity is reached when all reinforcement has been corroded. On the other hand, when more extensive corrosion occur, the tension force is affected by the bond between concrete and steel. In this case, much smaller losses in area can cause complete debond between concrete and steel, and make the reinforcement ineffective. In this case, the loss of strength in much faster, and for corrosion levels close to $30 \%$ the stress in steel is negligible. The residual capacity is therefore provided by the non-corroded inner reinforcement layers.

Results, neglecting deterioration and the loss of bond between reinforcement and concrete are also plotted and compared. Disregarding the debonding effect, the probability of failure, in a logarithmic scale, increase linearly due to the loss of rebars cross section. Both the probability of failure and the reliability index remain constant when neglecting deterioration due to the problem time-independence. Results show that debonding as a crucial role in the safety reduction, at least initially, as has been suggested by several researchers (Al-Sulaimani et al., 1990; Almusallam et al., 1996; Mangat and Elgarf, 1999; Azher, 2005; Al-Hammoud et al., 2010; Kivell et al., 2012). Corrosion levels above $50 \%$ show that the probability of failure and the reliability index remain almost constant, due to the weak adherence to concrete. Thus, 
even if rebars are still corroding, they are no longer adherent to concrete. However, it must be highlighted in this stage, that corrosion was limited to the outer layer of bottom reinforcement, and the inner layers were considered fully encased in concrete and completely intact. In fact, the scenario of important corrosion in the inner bars is very unlikely to occur as a maintenance intervention will be executed before this happens due to the complete absence of the first layer of rebars as well as extensive cracking in the bottom area of the girders.

The different corrosion levels observed during the inspection carried out and the impact of the bridge deck redundancy, on the probability of failure (Figure 8) and reliability index were also analysed. Corrosion was roughly estimated to be less severe on girders 2 to 4 , as no quantitative measure exists. Consequently, four additional case scenarios were considered by defining corrosion levels in girders 2 to $4, X_{P_{2,3}, 4}$, as a fraction of the corrosion depth in girder $1, X_{P 1}$, as: $X_{P_{2,3,4}}=0.75 X_{P_{1}}, X_{P_{2,3,4}}=0.50 X_{P_{1}}, X_{P_{2,3,4}}=0.25 X_{P_{1}}$, $X_{P_{2,3,4}}=0$. The safety was also analyzed considering an element based approach. In this case, girders 1 and 2, were analysed independently, considering no load transfer between girders.

[Figure 8 about here.]

Results presented in Figures 8 show that the probability of failure and the reliability index are significantly reduced and increased, respectively, when less corrosion is considered on girder 2 to 4 in relation to that of girder 1. This can be explained due to the load transfer to the less corroded and less loaded girders. The probability of failure is also greatly increased when girder 1 and 2 are analysed independently. The latter correspond to the 
worst case since it is that subjected to heavier loads. In both cases, no load transfer is possible to the adjacent girders which explains the higher probability of failure and the reduced reliability index. At the time the bridge was demolished the probability of failure of the bridge deck was assessed to be $5 \times 10^{-4}$, if girder 2 was analysed independently. This value can explain the decision of demolishing the bridge, however Figure 8 shows that for more advanced corrosion levels, the probability of failure remains almost constant, thus the situation would not be significantly worsen.

\subsection{Robustness Analysis}

The results of the reliability analysis presented in the previous section should be used with precaution since very significant uncertainty exists about the existing corrosion level. Thus the robustness analysis presented herein is advantageous since all possible corrosion levels are foreseen and translated on a single robustness index.

Figure 9 shows the normalized performance (reliability index) as a function of the damage level (corrosion on the reinforcement). Robustness was computed according to Equation (6) and resulted in 0.82 , which represents an average ratio between the performance of the damage and the intact structure, considering corrosion as unpredictable and ranging from [0-100]\%. As referred, this is supposed to be a relative measure developed having in the mind the comparison between the tolerance to different corrosion scenarios and/or different structures. Figure 9 also shows the case where no deterioration and no debonding have been considered. Robustness results equal to 1 and 0.90 , respectively, which depicts approximately the same relative importance of both the deteriorating mechanisms, the loss of cross section 
and the loss of bond.

[Figure 9 about here.]

Figure 10 shows the normalized performance as a function of the damaged level for the same cases of Figures 8. Table 2 summarizes the calculations of robustness following Equation (6).

[Figure 10 about here.]

Effects of system transverse redundancy can be observed by observing robustness increasing (up to a maximum of 0.95) as less corrosion is being considered on the girders adjacent to girder 1. Robustness of single girders resulted similar to that of the bridge deck when all the girders are equally corroded since only residual load transference between girders is possible.

[Table 2 about here.]

\subsection{Decision making based on robustness}

As mentioned, the uncertainty related to the effective corrosion level on existing structures is usually significant which makes difficult the process of decision making. The robustness measure presented herein was developed to assist structural assets management, as more robust structures present a better tolerance to damage and therefore require less maintenance, or at least sustain longer periods between maintenance actions. The robustness indicator can be used on either high-level or low-level decisions and on both planning and operation stages of a transportation network. Optimal highlevel decisions on maintenance and inspection should be based on the robustness index single value. Less robust structural types require increased 
investment for maintenance thus they should be avoided when planning a new infrastructure network in aggressive environments. For existing infrastructures, a higher budget percentage for maintenance should be devoted to the maintenance of the less robust structural typologies. For low-level optimal decision a deeper look into the performance curve is necessary. In terms of maintenance and inspections times, the performance curve for different structures, should be combined with different deterioration rates, damage scenarios, target safety levels (previously defined), including repair costs, to achieve an optimal decision.

Although this paper is based on a single structure, Table 2 shows that the bridge robustness is also dependent on the damage scenario. Robustness resulted lower for the cases of uniform corrosion and independent action of girders, and higher when the load transfer among girders was considered possible if only girder 1 was subjected to corrosion. Clearly an advantage could be taken from these results due to their impact on the time-dependent safety, when planning care and maintenance actions. Figure 11 shows the time-dependent probability of failure of Tercenas bridge, $P_{f}(0, t)$, referred to the time period $[0, t]$, where $t=0$ respects to the onset of corrosion and neglecting the initiation period. The lower and the upper bounds of the probability of failure resulted very narrow as weak dependency was found between different time periods. Thus, the bounds appear overlapped in Figure 11. The results in Table 2 and Figure 11 indicate that both the time-dependent analysis and the robustness-based analysis can characterize the dependency between safety and corrosion. However, the later indicator does not require the estimation of a deterioration or corrosion rate, which, as discussed above, 
is extremely difficult to predict, particularly at the design state. As expected, the probability of failure within the reference period increases at a faster rate when the single action of girder 1 and 2 is considered, or when all the girders are equally corroded (the three curves are parallel). These are the cases for which robustness resulted lower (see Table 2). On the other hand, when corrosion is considered to affect only girder 1 (case of maximum robustness), the time-dependent probability of failure increases at the most reduced rate approaching the case of no deterioration. Thus, a longer time for the first intervention could be defined depending on robustness.

[Figure 11 about here.]

Similarly, a longer time between periodic inspections could be adopted depending on robustness. Figure 12 shows the time-dependent probability of failure given the observed corrosion level at the inspection time and within the period between inspections, considered equal to 3 years, $P_{f}\left(3 y \mid X_{P}\right)$. Three corrosion scenarios are depicted, Uniform corrosion, $X_{P_{2,3,4}}=0.50 X_{P_{1}}$, and $X_{P_{2,3,4}}=0$, including a corrosion rate $\left(2 i_{\text {corr }}\right)$ twice of that observed in the Tercenas bridge. As observed, the impact of a higher corrosion rate reduces as robustness increases, and therefore, a longer time between inspections can be defined.

[Figure 12 about here.]

\section{Conclusions}

Although the robustness concept is often related to extreme events, it can also be useful to characterize structures tolerance to aging and deterioration, 
resulting in a fundamental tool in structural management systems. The framework proposed by Cavaco et al. (2013b) serve this propose and was extended in this paper to assess robustness of Tercenas Bridge. This bridge was inspected in March 2011 revealing advanced corrosion levels on the deck girders, in particular in girder 1 , leading to the bridge demolition based on its condition state in November 2012.

Performed robustness analysis of the bridge deck subjected to girders uniform corrosion resulted in a robustness index of 0.82 . This value translates the tolerance to corrosion as it represents the mean reliability of the corroded structure in relation to that intact, considering corrosion as unpredictable or, in other words, accepting that the future performance profile is almost unknown, as it is normally the case due to the difficulties in predicting future corrosion for all nowadays available models for corrosion deterioration

The results show that the bridge has very significant robustness to corrosion, as a result of its redundancy, ability to distribute loads in the transversal direction and remaining capacity of the less deteriorated girders. The proposed robustness indicator is capable of capturing these effects, indicating that the bridge is safe, in spite of the clear signs of deterioration. In the theoretical scenario where girder 2 to 4 remain intact, robustness of the bridge deck resulted equal to 0.95 .

An element based approach show that the reliability of a single girder is much below that of the bridge deck. However, their robustness is similar if the latter is subjected to uniform corrosion. Robustness of the bridge deck resulted superior to that of a single girder when load transfer to less corroded girders is possible. 
Results also show that the increasing rate of the probability of failure within the structure life-time or the period between inspections is reduced for cases of superior robustness. More robust structures allow longer times for the first intervention and between periodic inspections. Therefore, although the performance profile of the bridge is not known, which is essential for correct decision making within a bridge management system framework, the obtained robustness is of a great help for decision makers regarding its prospective future performance and therefore, the inspection and maintenance actions to be undertaken.

The analysis presented in this paper showed that structural management based only on structural condition is not the best strategy when budget is limited, as it do not takes advantage on robustness and the structures tolerance to sustain damage without significant safety reductions. To take advantage of such robustness (tolerance to damage), it is proposed to include the robustness index (6) in the service-life management of existing structures. For example, when different structures present similar damage, but they have different robustness index, or when similar structures are subjected to different damage scenarios, those with higher robustness may wait longer until intervention is carried out, therefore helping to rearrange or modify the maintenance/repair planning on the basis of the available budget.

\section{Acknowledgments}

The authors would like to acknowledge Cost Action TU-0601, Fundação para a Ciência e Tecnologia scholarchip SFRH/BD/45799/2008 and Research Project PTDC/ECM-COM/2911/2012, CEris - Civil Engineering Research 
and Innovation for Sustainability and the Spanish Ministry of Education (Research Project BIA2010-16332).

\section{References}

Akiyama, M., Frangopol, D. M., Yoshida, I., 2010. Time-dependent reliability analysis of existing rc structures in a marine environment using hazard associated with airborne chlorides. Engineering Structures 32 (11), 37683779 .

Al-Hammoud, R., Soudki, K., Topper, T. H., Mar. 2010. Bond analysis of corroded reinforced concrete beams under monotonic and fatigue loads. Cement and Concrete Composites 32 (3), 194-203, 00025.

Al-Sulaimani, G., Kaleemullah, M., Basunbul, I., 1990. Influence of corrosion and cracking on bond behavior and strength of reinforced concrete members. ACI Structural Journal 87 (2).

Alipour, A., Shafei, B., Shinozuka, M. S., 2013. Capacity loss evaluation of reinforced concrete bridges located in extreme chloride-laden environments. Structure and Infrastructure Engineering 9 (1), 8-27.

Almusallam, A., Al-Gahtani, A., Aziz, A., 1996. Effect of reinforcement corrosion on bond strength. Construction and Building Materials 10 (2), 123129.

Amleh, L., Mirza, S., 1999. Corrosion influence on bond between steel and concrete. ACI Structural Journal 96 (3), 415-423.

ASCE, 2013. 2013 Report Card for America's Infrastructure. Tech. rep. 
Auyeung, Y., Balaguru, P., Chung, L., 2000. Bond behavior of corroded reinforcement bars. ACI Materials Journal 97 (2), 214-220.

Azher, S. A., 2005. A Prediction model for the residual flexural strength of corroded reinforced concrete Beams. MSc thesis, King Fahd University of Petroleum and Minerals, Dhahran, Saudi Arabia.

Baker, J., Schubert, M., Faber, M., 2008. On the assessment of robustness. Structural Safety 30 (3), 253-267.

Bhargava, K., Ghosh, A., Mori, Y., Ramanujam, S., 2007. Corrosion-induced bond strength degradation in reinforced concrete-analytical and empirical models. Nuclear Engineering and Design 237 (11), 1140-1157.

Biondini, F., 2009. A measure of lifetime structural robustness. In: Proceedings of the SEI/ASCE Structures Congress.

Biondini, F., Frangopol, D. M., 2014. Time-variant robustness of aging structures. Maintenance and Safety of Aging Infrastructure: Structures and Infrastructures Book Series 10, 163.

Biondini, F., Restelli, S., 2008. Damage propagation and structural robustness. In: Life-Cycle Civil Engineering: Proceedings of the International Symposium on Life-Cycle Civil Engineering, IALCCE'08, Varenna, Lake Como. Taylor \& Francis, p. 131.

Biondini, F., Vergani, M., 2015. Deteriorating beam finite element for nonlinear analysis of concrete structures under corrosion. Structure and Infrastructure Engineering 11 (4), 519-532. 
Bucher, C., 2009. Computational Analysis of Randomness in Structural Mechanics: Structures and Infrastructures Book Series. Vol. 3. CRC.

Cabrera, J., 1996. Deterioration of concrete due to reinforcement steel corrosion. Cement \& Concrete Composites 18 (1), 47-59.

Cavaco, E. S., Casas, J. R., Neves, L. A., 2013a. Quantifiying redundancy and robustness of structures. In: Proceedings of IABSE Workshop on safety, failures and robustness of large structures. Helsinki, Finland.

Cavaco, E. S., Casas, J. R., Neves, L. A., Huespe, A. E., 2013b. Robustness of corroded reinforced concrete structures-a structural performance approach. Structure and Infrastructure Engineering 9 (1), 42-58.

Cavaco, E. S., Neves, L. A., Casas, J. R., 2016. A reliability-based approach to the robustness of corroded rc structures. Structural Concrete, doi:10.1002/suco.201600084.

CEN, 2002. Eurocode 1: Actions on structures; Part 2: EN 1991-2 Traffic loads on bridges. Brussels (Belgium):Comite European de Normalization 250 .

Cremona, C., Kaschner, R., Daly, A., October 1999. Deliverable D5: Development of models (loads and strength). Tech. rep., BRIME.

Ditlevsen, O., 1979. Narrow reliability bounds for structural systems. Journal of structural mechanics 7 (4), 453-472.

Faber, M., Vrouwenvelder, A., 2000. Probabilistic model code. Tech. rep., Technical report, Joint Committee on Structural Safety, 2000. 
Fang, C., Lundgren, K., Chen, L., Zhu, C., 2004. Corrosion influence on bond in reinforced concrete. Cement and concrete research 34 (11), 2159-2167.

Frangopol, D. M., Curley, J. P., 1987. Effects of damage and redundancy on structural reliability. Journal of Structural Engineering 113 (7), 1533-1549.

Ghosn, M., Moses, F., 1998. NCHRP Report 406: Redundancy in Highway Bridge Superstructures. Transportation Research Board, National Research Council, Washington, DC.

Gonzalez, J., Andrade, C., Alonso, C., Feliu, S., 1995. Comparison of rates of general corrosion and maximum pitting penetration on concrete embedded steel reinforcement. Cement and Concrete Research 25 (2), 257-264.

Haldar, A., Mahadevan, S., 2000. Probability, reliability, and statistical methods in engineering design. John Wiley \& Sons, Incorporated.

Jacinto, L., 2011. Safety assessment of existing bridges. bayesian probabilistic approach. Ph.D. thesis, FCT/UNL (in portuguese).

Kivell, A., Palermo, A., Scott, A., Mar. 2012. Corrosion Related Bond Deterioration and Seismic Resistance of Reinforced Concrete Structures. In: Structures Congress 2012. American Society of Civil Engineers, pp. 18941905, 00001.

Lee, H., Noguchi, T., Tomosawa, F., 2002. Evaluation of the bond properties between concrete and reinforcement as a function of the degree of reinforcement corrosion. Cement and Concrete research 32 (8), 1313-1318. 
Lim, S., Akiyama, M., Frangopol, D. M., 2016. Assessment of the structural performance of corrosion-affected rc members based on experimental study and probabilistic modeling. Engineering Structures 127, 189-205.

Lind, N., 1995. A measure of vulnerability and damage tolerance. Reliability engineering \& systems safety 48 (1), 1-6.

Mangat, P., Elgarf, M., 1999. Flexural strength of concrete beams with corroding reinforcement. ACI Structural Journal 96 (1).

Mazzoni, S., McKenna, F., Scott, M., Fenves, G., et al., 2005. Opensees command language manual. Pacific Earthquake Engineering Research (PEER) Center.

Melchers, R. E., 1999. Structural reliability analysis and prediction. John Wiley \& Son Ltd.

Murakami, Y., Kinoshita, A., Suzuki, S., Hukumoto, Y., Oshita, H., 2006. Influence of lapped splices on residual flexural behavior of rc beams with corrosion of reinforcement. Concrete Research and Technology 17 (1).

Oliver, J., Linero, D., Huespe, A., Manzoli, O., 2008. Two-dimensional modeling of material failure in reinforced concrete by means of a continuum strong discontinuity approach. Computer Methods in Applied Mechanics and Engineering 197 (5), 332-348.

Olsson, A., Sandberg, G., Dahlblom, O., 2003. On Latin hypercube sampling for structural reliability analysis. Structural Safety 25 (1), 47-68. 
Papakonstantinou, K., Shinozuka, M., 2013. Probabilistic model for steel corrosion in reinforced concrete structures of large dimensions considering crack effects. Engineering Structures 57, 306-326.

Pina, J., 2009. Structural assessment of corroded rc structures through numerical modelling. Ph.D. thesis, IST, University of Lisbon, Portugal.

Rodriguez, J., Ortega, L., Casal, J., 1994. Corrosion of reinforcing bars and service life of $\mathrm{r} / \mathrm{c}$ structures: corrosion and bond deterioration. In: Concrete across Borders, Proceedings, Odense, Denmark. Vol. II.

Rodriguez, J., Ortega, L., Casal, J., Diez, J., 1996. Corrosion of reinforcement and service life of concrete structures. 7th International Conference on Durability of building materials and components.

Schroeder, R., Müller, I., 2003. Stress corrosion cracking and hydrogen embrittlement susceptibility of an eutectoid steel employed in prestressed concrete. Corrosion science 45 (9), 1969-1983.

Starossek, U., Haberland, M., 2011. Approaches to measures of structural robustness. Structure and Infrastructure Engineering 7 (7-8), 625-631.

Stewart, M. G., 2004. Spatial variability of pitting corrosion and its influence on structural fragility and reliability of rc beams in flexure. Structural Safety $26(4), 453-470$.

Stewart, M. G., Al-Harthy, A., 2008. Pitting corrosion and structural reliability of corroding rc structures: Experimental data and probabilistic analysis. Reliability Engineering \& System Safety 93 (3), 373 - 382, probabilistic Modelling of Structural Degradation. 
Stewart, M. G., Rosowsky, D. V., 1998. Time-dependent reliability of deteriorating reinforced concrete bridge decks. Structural Safety 20 (1), 91 109.

Tang, A.-S. A. W., Ang, A., 2006. Probability concepts in engineering: Emphasis on applications in civil \& environmental engineering.

Val, D. V., Stewart, M. G., Melchers, R. E., 1998. Effect of reinforcement corrosion on reliability of highway bridges. Engineering Structures 20 (11), $1010-1019$.

von Scholten, C., Enevoldsen, I., Arnbjerg-Nielsen, T., et al., 2004. Reliability-based classification of the load carrying capacity of existing bridges, report 291'. Tech. rep.

Vrouwenvelder, T., 1997. The JCSS probabilistic model code. Structural Safety 19 (3), 245-251.

Woodtli, J., Kieselbach, R., 2000. Damage due to hydrogen embrittlement and stress corrosion cracking. Engineering Failure Analysis 7 (6), 427-450.

Yassin, M., 1994. Nonlinear Analysis of Prestressed Concrete Structures under Monotonic and Cycling Loads. PhD dissertation, University of California, Berkeley. 


\section{List of Figures}

1 Slipping-fiber model constitutive behavior. . . . . . . . . . . . 41

2 Tercenas bridge lateral view. . . . . . . . . . . . . . . . 42

3 Bridge deck cross section at mid span and supports. . . . . . . 43

4 Corrosion affecting girders 1 to 4 . . . . . . . . . . . . . . . 44

5 Exposed reinforcement on Girder 1. . . . . . . . . . . . 45

6 OpenSees frame based finite element model. . . . . . . . . . . 46

7 Probability of failure of Tercenas Bridge and reliability index, depending on the corrosion level. . . . . . . . . . . . . 47

8 Probability of failure of Tercenas Bridge for different corrosion scenarios. . . . . . . . . . . . . . . . . . . . . . . . 48

9 Tercenas Bridge normalized performance depending on damage level. . . . . . . . . . . . . . . . . . . . . . . . . . . . . . 49

10 Performance of Tercenas Bridge under different corrosion scenarios. . . . . . . . . . . . . . . . . 50

11 Time-dependent probability of failure of Tercenas Bridge. . . . 51

12 Probability of failure of Tercenas Bridge for time between inspections, depending on the corrosion rate. . . . . . . . . . 52 


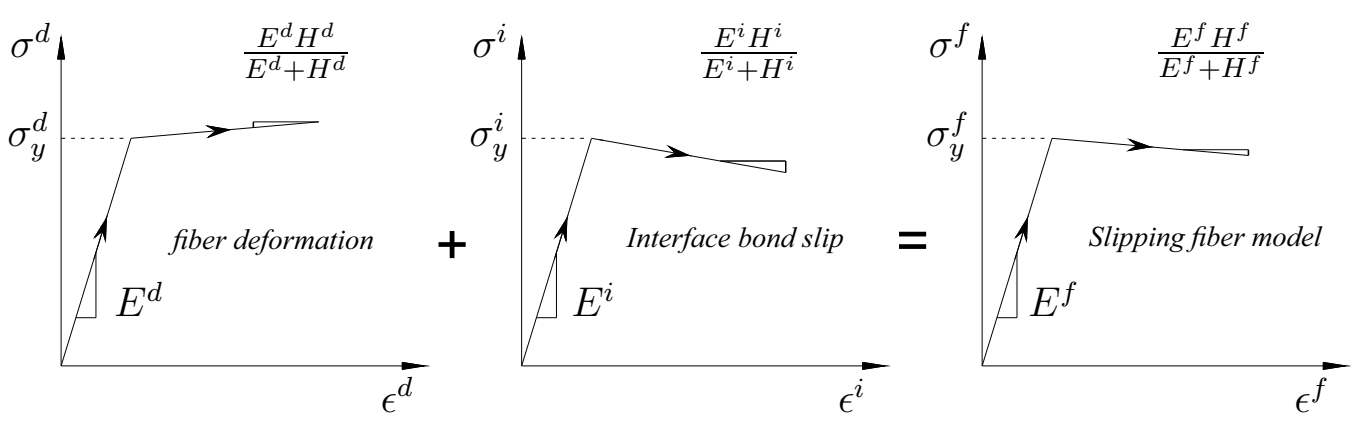

Figure 1: Slipping-fiber model constitutive behavior. 


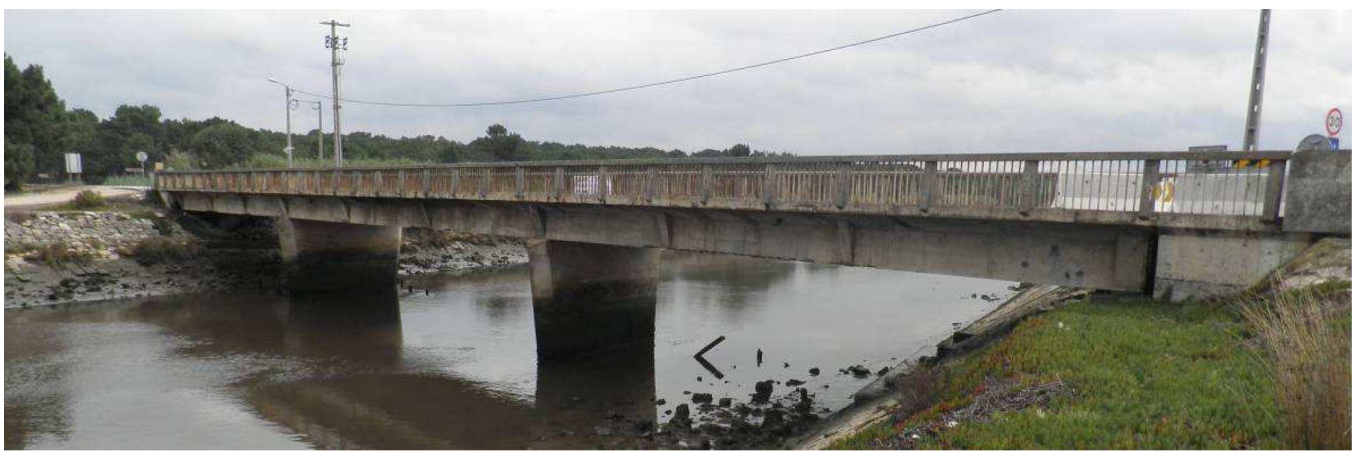

Figure 2: Tercenas bridge lateral view. 


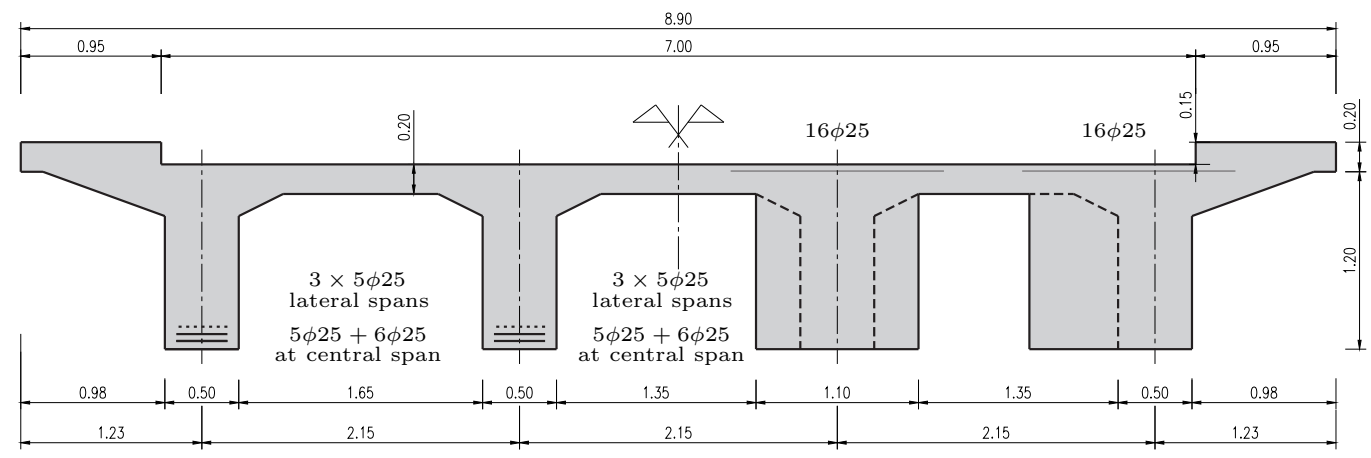

Cross section at mid span

Cross section at supports

Figure 3: Bridge deck cross section at mid span and supports. 


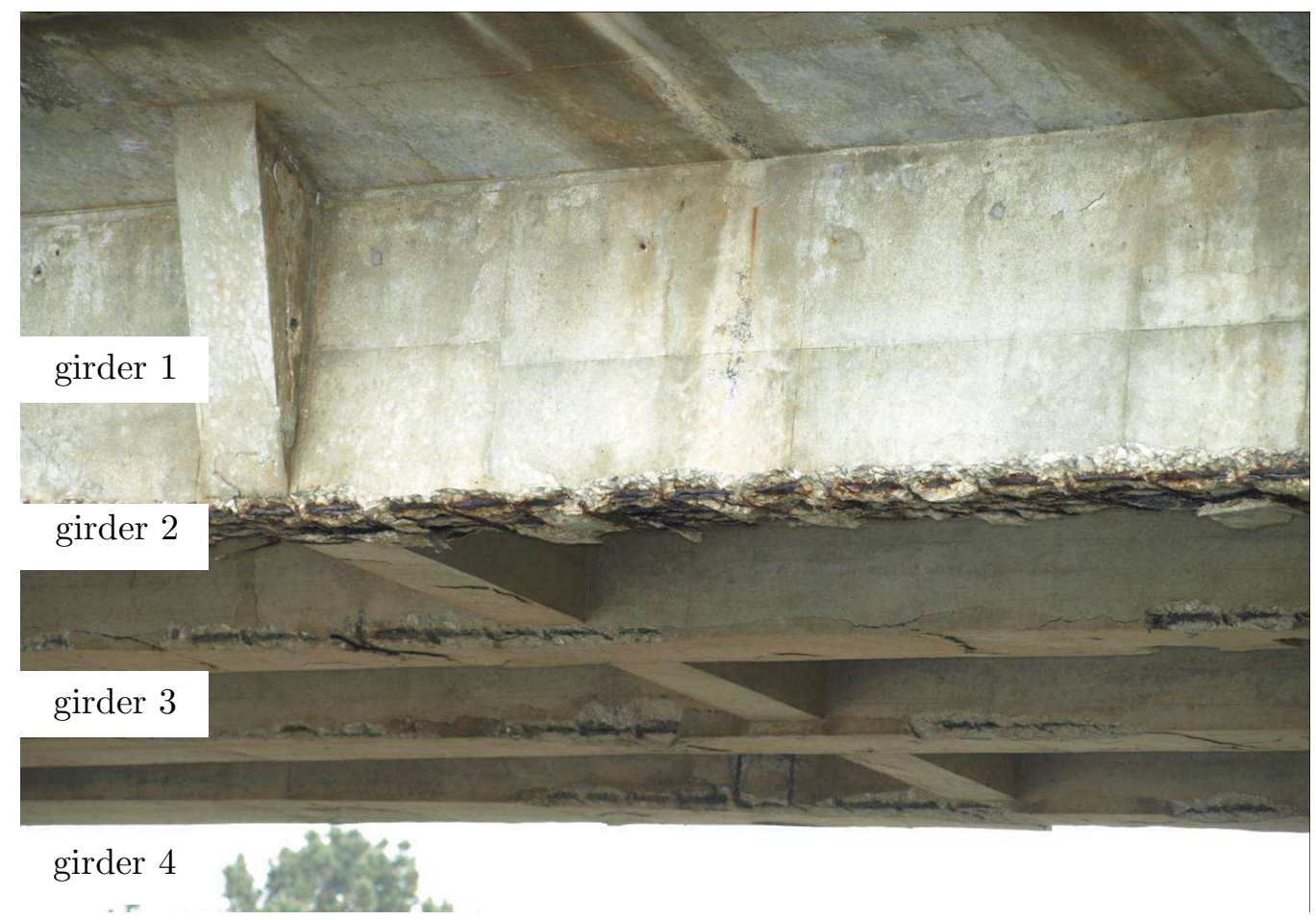

Figure 4: Corrosion affecting girders 1 to 4 . 


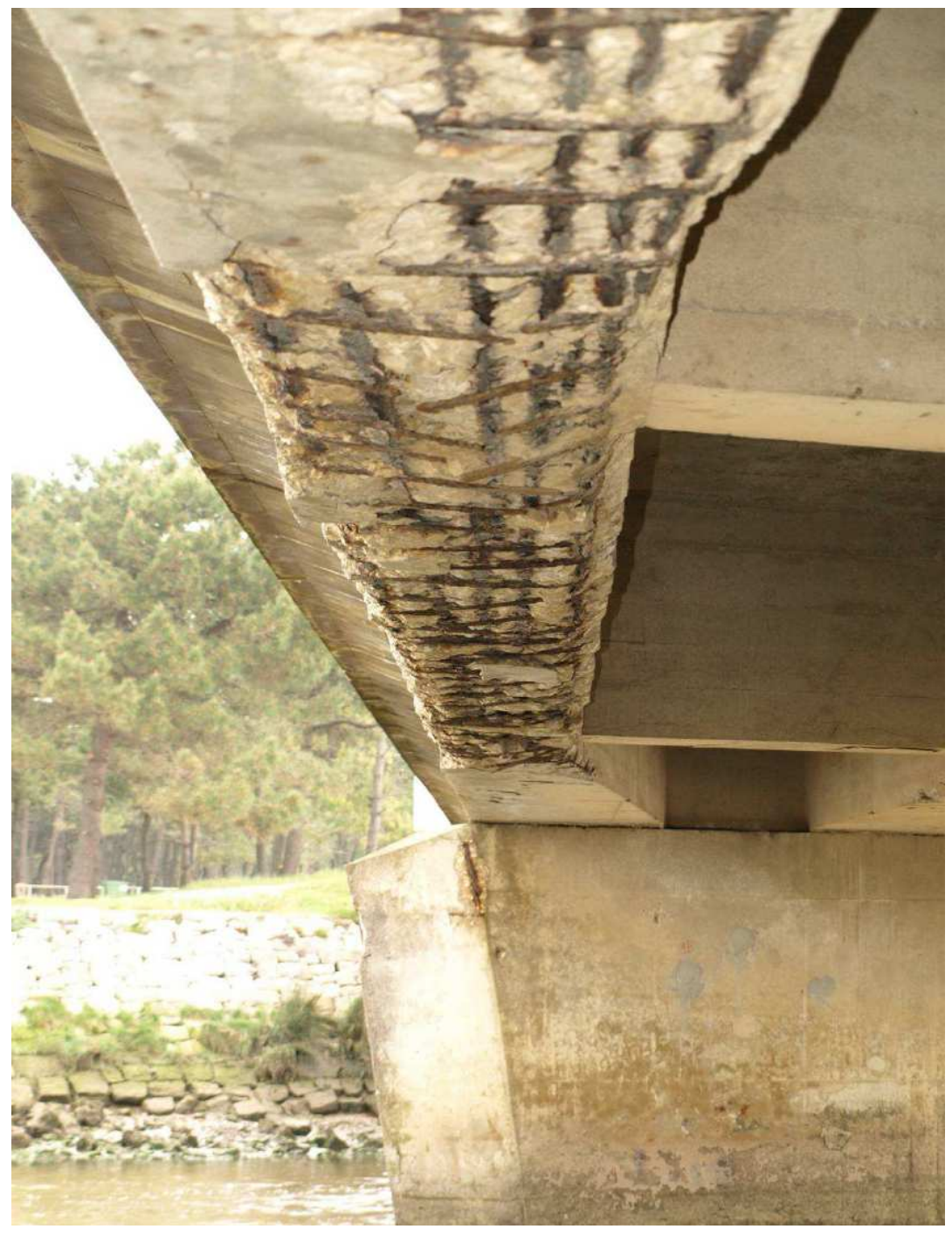

Figure 5: Exposed reinforcement on Girder 1. 


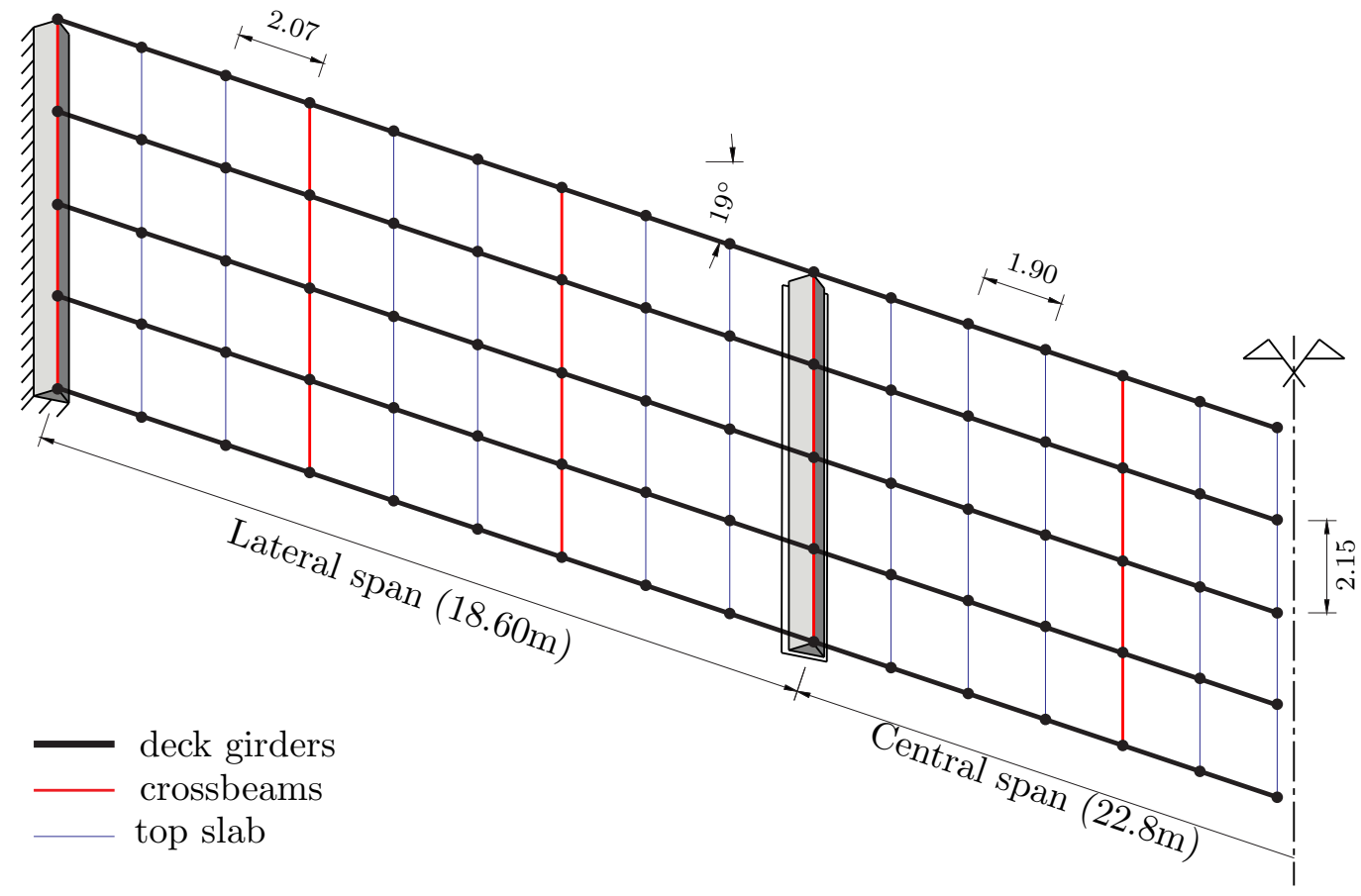

Figure 6: OpenSees frame based finite element model. 


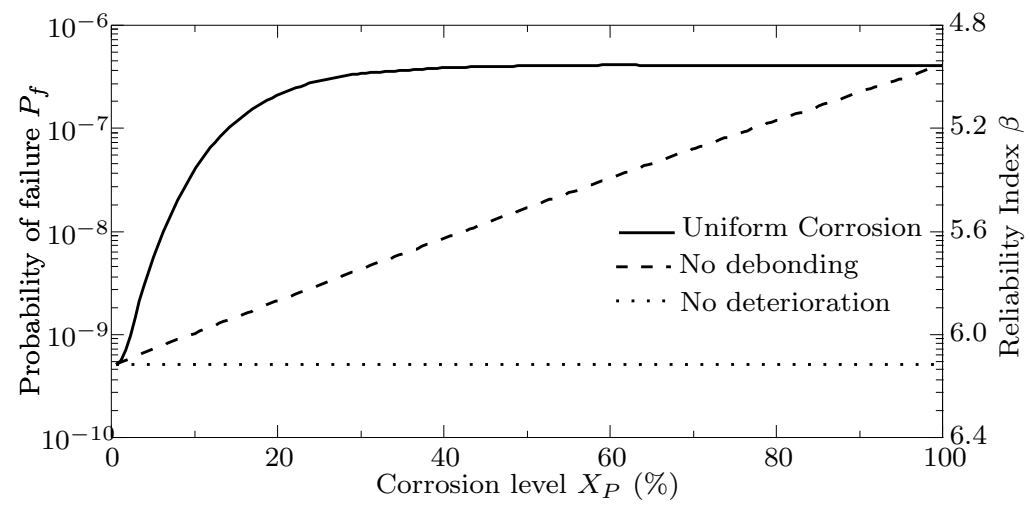

Figure 7: Probability of failure of Tercenas Bridge and reliability index, depending on the corrosion level. 


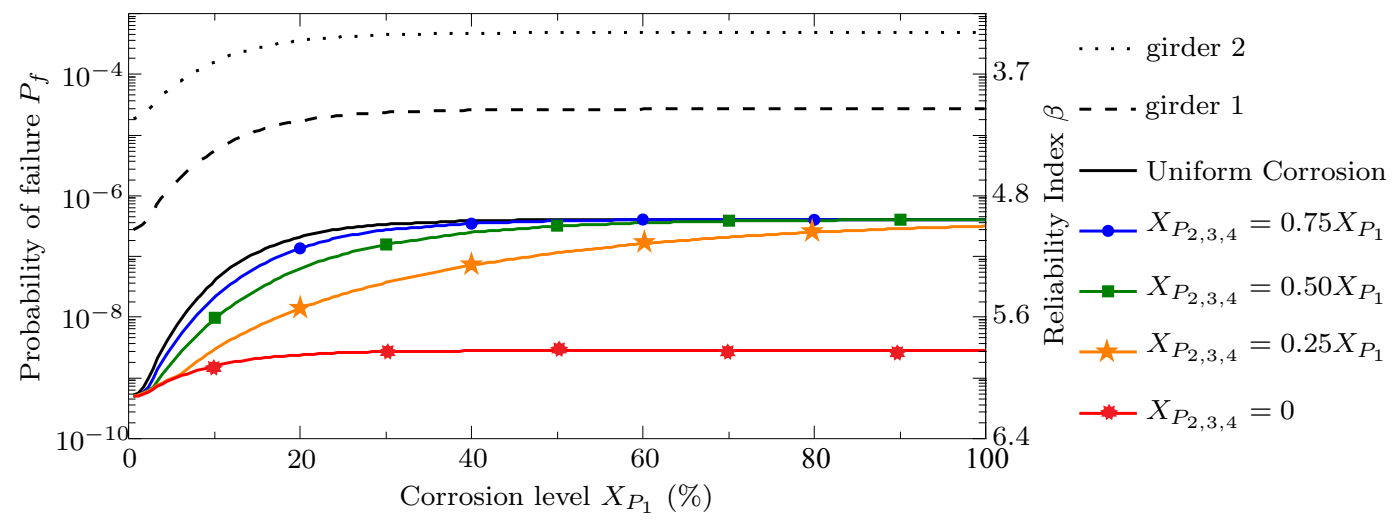

Figure 8: Probability of failure of Tercenas Bridge for different corrosion scenarios. 


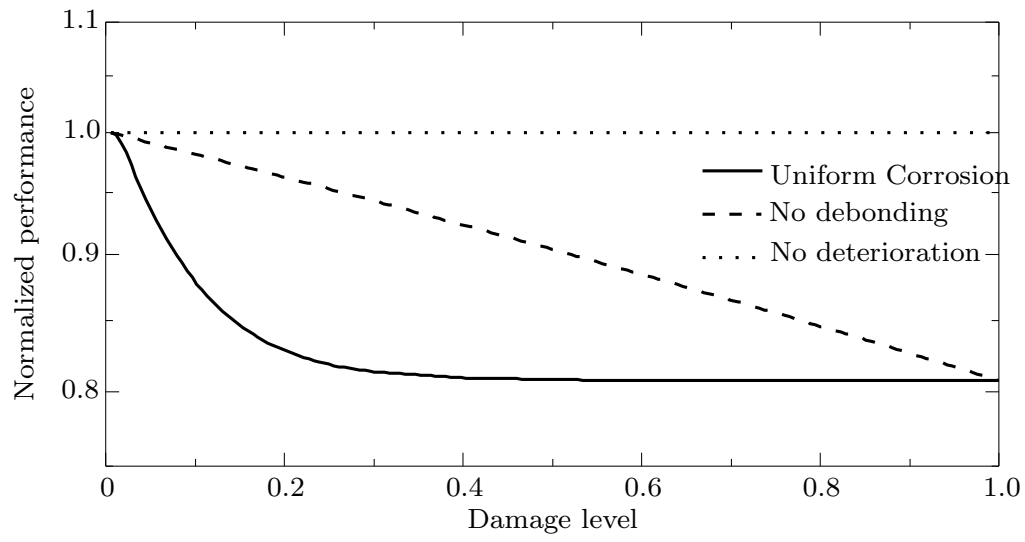

Figure 9: Tercenas Bridge normalized performance depending on damage level. 


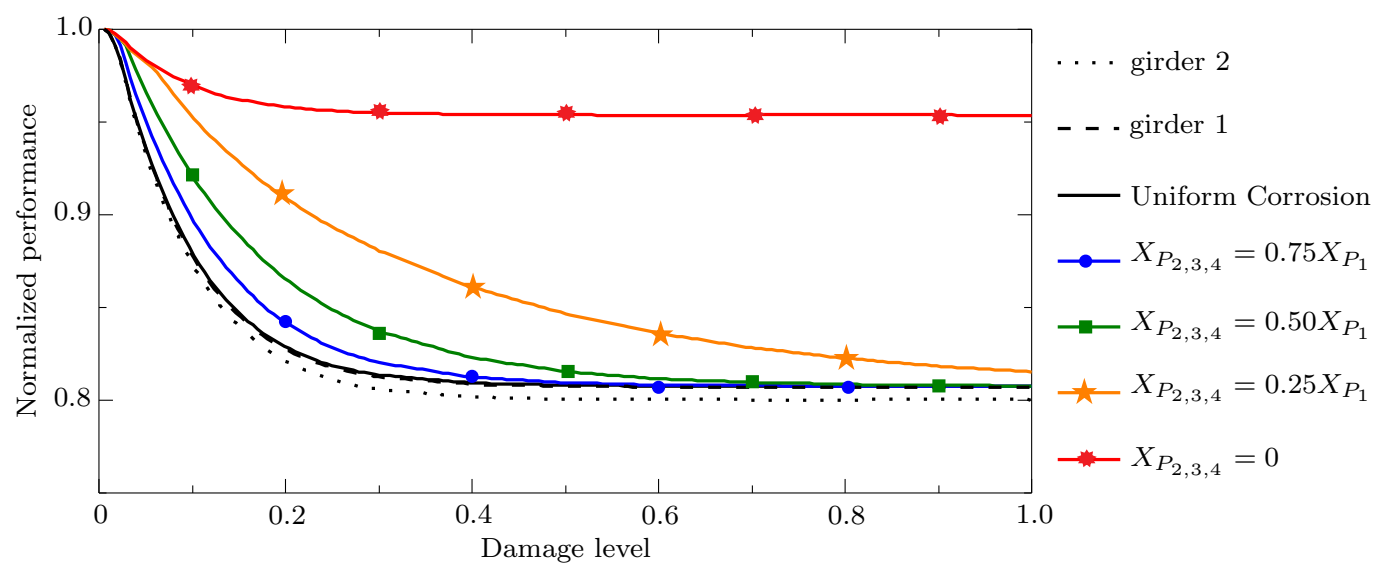

Figure 10: Performance of Tercenas Bridge under different corrosion scenarios. 


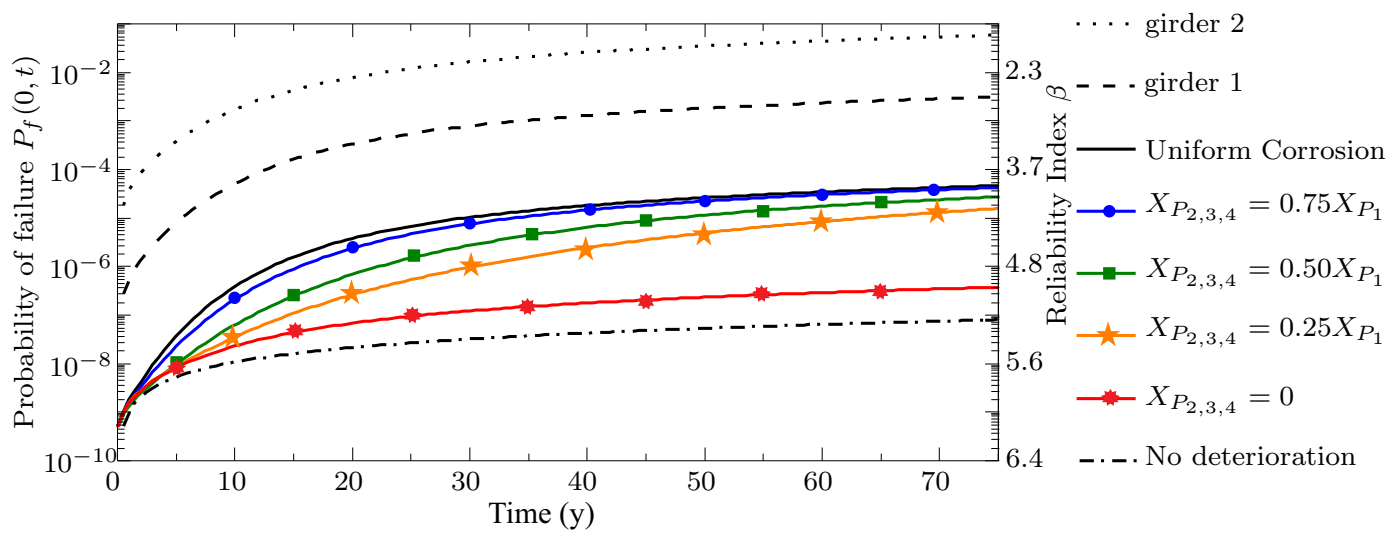

Figure 11: Time-dependent probability of failure of Tercenas Bridge. 


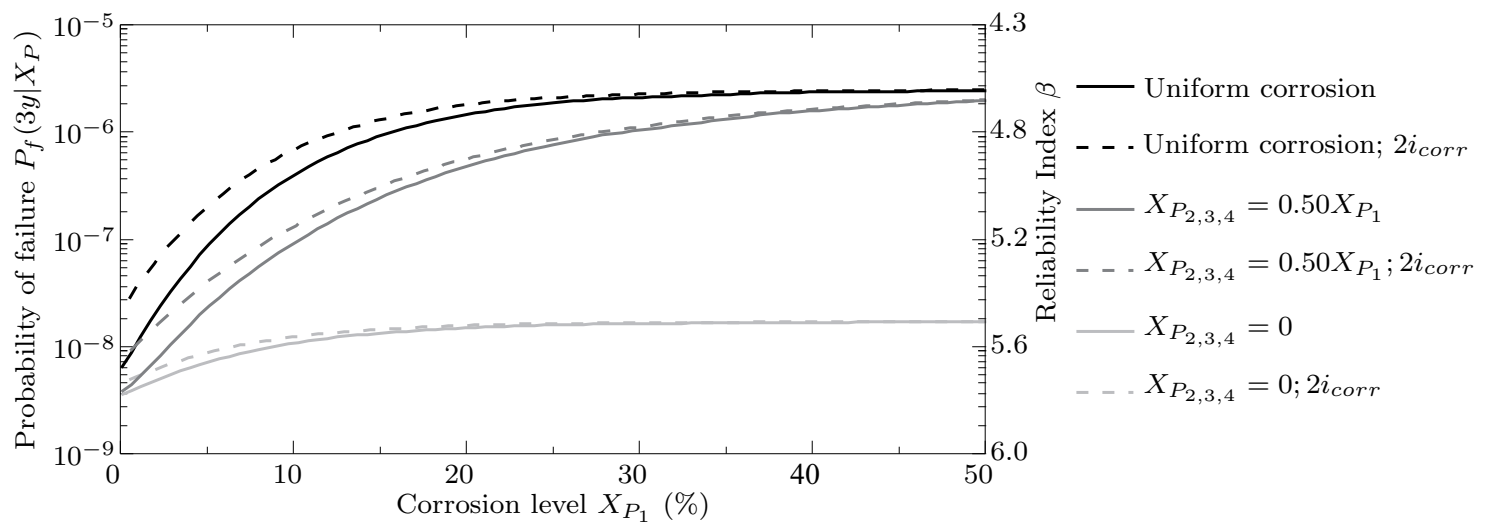

Figure 12: Probability of failure of Tercenas Bridge for time between inspections, depending on the corrosion rate. 


\section{List of Tables}

1 Random variables distributions and parameters. . . . . . . . . 54

2 Tercenas bridge robustness assessment. . . . . . . . . . 55 
Table 1: Random variables distributions and parameters.

\begin{tabular}{lccc}
\hline Random Variable & Distribution & Mean & $\begin{array}{c}\text { Standard } \\
\text { Deviation }\end{array}$ \\
\hline Concrete strength, $f_{c}$ & lognormal & $51.2 \mathrm{MPa}$ & $13.2 \mathrm{MPa}$ \\
Steel yielding stress, $f_{y}$ & normal & $460 \mathrm{MPa}$ & $30 \mathrm{MPa}$ \\
Reinforcement bars area, $A_{s}^{\phi 25}$ & normal & $4.91 \mathrm{~cm}^{2}$ & $0.098 \mathrm{~cm}^{2}$ \\
Resistance model uncertainties, $\theta_{R}$ & lognormal & 1.05 & 0.105 \\
Concrete self-weight, $\gamma_{c}$ & normal & $25 \mathrm{kN} / \mathrm{m}^{3}$ & $0.75 \mathrm{kN} / \mathrm{m}^{3}$ \\
Dead loads, $\gamma_{d l}$ & normal & - & $0.10 \mu_{\gamma_{d l}}$ \\
Maximum Traffic loads $(100$ years $) \gamma_{t l}$ & gumbel & 0.728 & 0.146 \\
Load model uncertainties, $\theta_{E}$ & lognormal & 1.0 & 0.100 \\
\hline
\end{tabular}


Table 2: Tercenas bridge robustness assessment.

\begin{tabular}{lc}
\hline Case & $R$ \\
\hline Uniform Corrosion & 0.82 \\
No debonding & 0.90 \\
No deterioration & 1.00 \\
$X_{P_{2,3,4}}=0.75 X_{p_{1}}$ & 0.83 \\
$X_{P_{2,3,4}}=0.50 X_{p_{1}}$ & 0.84 \\
$X_{P_{2,3,4}}=0.25 X_{p_{1}}$ & 0.87 \\
$X_{P_{2,3,4}}=0$ & 0.95 \\
girder 1 & 0.82 \\
girder 2 & 0.81 \\
\hline
\end{tabular}

